\title{
Interview with the Hon. Nicola Roxon: getting evidence into health policy
}

\author{
Nicola Roxona,b \\ a Minister for Health and Ageing (2007-2011), Australian Government, Canberra, ACT \\ b Sir Zelman Cowen Centre, Victoria University, Melbourne, Australia
}

\section{Article history}

Publication date: February 2017

Roxon N. Interview with the Hon. Nicola Roxon: getting evidence into health policy. Public Health Res Pract. 2017;27(1):e2711701. doi: http://dx.doi. org/10.17061/phrp2711701

\section{Key points}

- Working with decision makers to implement new health policy often involves finding a political 'sweet spot' where a good policy decision is also good politics

- When communicating a new idea to a minister or decision maker, health advocates should aim to capture the imagination of the decision maker rather than overwhelm them with years of indepth research

- Plain packaging for tobacco products is a great example of implementing good health policy where trusted health organisations worked across political groups, provided expert research and supported the government to take action

\section{Introduction}

Public health researchers and practitioners want to see their research inform government decision making. It is not always clear to researchers how evidence is used in policy decisions in a highly politicised environment with many competing demands. We spoke to the Honourable Nicola Roxon, former Australian Minister for Health and Ageing (2007-2011), to gain some insight into the process, and advice on how to engage most productively with government.

Q: Often ministers and policy makers must try to make good policy decisions in areas where evidence is incomplete or contested. What strategies or processes did you employ when trying to make good public health decisions at a federal level when the evidence was insufficient? What were the main challenges involved and how did you overcome them?

A: I think it is very rare for ministers or governments to want to make decisions where evidence is incomplete or contested (provided the contest is real, not fabricated by vested interests). There are so many competing, worthy, evidence based causes - especially in health - that these will usually be given priority. However, in a crowded political agenda, having a worthy cause isn't always enough to capture the imagination of government. The biggest single mistake I saw when I was Health Minister was repeated over and over again, by decent, hard-working researchers, medicos and advocates - and it was the naive assumption that, because they were working on something good, or had developed a worthy project, the government would therefore act on it.

As a minister, I was able to act on some fabulous ideas, and I'm proud of that. But many good ideas were not acted upon - often because of financial constraints, but also many other reasons played a role.

Just because your idea is good, even worthy, isn't enough.

Q: So, how does evidence inform policy decisions in the real world?

A: To get real decisions and actions in your area, you must think closely and carefully about who you are putting your evidence to, their needs and priorities, and why your proposal will help them. In a world where most interventions cost money - and, in health, usually a lot of money - simply appealing to their good nature is too simplistic. You need to make it easy for 
decision makers to see how acting on your idea is worth taking up time, money and political energy.

Knowing what is going on in the decision maker's portfolio, what is troubling them, what is taking up their time and giving them sleepless nights helps you find a way to fit your issue into their thinking space. Start by putting yourself in the position of the minister you want to take action. Do you know what they are trying to achieve? Have you read any of their speeches or policies or recent interviews? Demonstrating your understanding of their issues and pressures is good manners, but also helps you shape your pitch to their current interests or pressures.

For example, when the Australian Government announced health reform negotiations with the states, a few groups came to us with proposals that could be part of those discussions. Not all were successful, but it showed they were tuned in to opportunities, and ready to make the most of them in a way that might suit government.

Even a scandal or problem can sometimes be a chance to offer a helpful solution. It might help solve the problem, or detract from it! Either way, this might be welcome.

The more in tune you are with the decision maker's pressures, the more likely you are to be agile and think laterally, to find good opportunities to raise your cause at the right time.

Q: When these opportunities present themselves, what is the best way to communicate?

A: Are you clear on what you would say and how you would say it if you got a brief chance to pitch your idea? A lot of people talk about having an 'elevator pitch' - this is the idea of what you would say if you were, by good luck, in an elevator with the decision maker. Could you explain your idea simply? And quickly enough?

The aim is to first capture the imagination of the decision maker - get them to be interested in your idea, impressed with your focus and your offer to help them.

I had too many meetings to recall where people tried to download 20 years of in-depth research in a 10-minute meeting - the minister needs to know it is there, to appreciate your expertise or credibility, but they don't need to be able to present a paper on it to the next technical meeting of the World Health Organization (WHO)!

Stick to the headline message or your core thesis to support a proposal - then you can leave the detailed summary for an adviser or official to mull over.

What you want from your meeting is to spark enough interest that the minister asks for more work to be done on your issue - not that they decide to write a book on it. Worse, your clear message will be diluted or lost if you try to do too much in a short meeting.
Q: What do you say to the researchers who feel that their work is ignored?

A: I am frustrated that governments are almost universally criticised for not taking action on public health. Sometimes that criticism of governments is fair and well based. We are right to expect courage and leadership from our governments. But, in truth, criticism of governments is also sometimes lazy. It can be easier to criticise a government for not acting on your issues than to ask whether you've done all you can to help them take that decision.

From the perspective of a former minister, I want to urge researchers, advocates and clinicians to assess whether they have done all they can to create a fertile environment to encourage government leadership. When they do, governments will provide leadership.

$\mathbf{Q}$ : Can you give an example of this more courageous leadership during your time as minister?

A: One example is a cause close to my heart: Australia's introduction of plain packaging for tobacco products. We are proud to be world leaders in introducing our shocking and ugly plain packs, and even more proud of the lively discussion and action it is generating elsewhere around the world on the future of tobacco control.

I have been very flattered, and often overwhelmed, by the recognition I get from introducing this measure. But the truth that ought to be acknowledged is that there were many people and many factors that made this courageous public health decision a good one for government, and easier than people imagine.

What made us choose this courageous path, when there were so many other competing issues on the table? It offers a good case study about advocacy.

The work of so many researchers, advocates, doctors, past governments, journalists and ordinary Australians moved this seemingly courageous decision into a political 'sweet spot'. Ultimately, it was a good policy decision that was good politics too.

It was an inexpensive policy with high impact; a policy with lots of supporters and a disliked opponent (the tobacco industry); a highly visible policy that complemented other measures important to the government, but perhaps less 'sexy'.

On each of these issues, advocates and supporters of the initiative sought to make the necessary links to our broader health reforms, our fresh focus on prevention and our interest in Indigenous health.

And it helped that the public had responded well in the past to tobacco control interventions, showing the huge benefits of a comprehensive approach to tobacco control measures. The research was strong, and the international treaty on tobacco (the WHO Framework Convention on Tobacco Control) supportive. 
Q: What role would you expect from civil society in this process?

A: The Cancer Council and Heart Foundation in Australia were the rolled-gold best examples of this on plain packaging - they worked across political groups, and had expert research as well as highly responsive media teams. They are trusted voices for consumers and were prepared to use that voice to not just criticise, but to help government act, as well. Their expertise and advice were vital.

Their advice on potential problems was also invaluable to the government. In tobacco control, you need a good working knowledge of international tobacco control developments and global industry tactics. Being carefully prepared for attacks is smart for governments, but just as vital is for other civil society participants to be ready to explain to the media or to parliamentary committees.

Q: What of more contested issues, such as alcohol regulation and tackling obesity in the population?

A: In Australia, it has been harder to garner support for strong interventions on alcohol and obesity. On obesity in particular, the mixed approaches from advocates and researchers about what is needed to be successful have made it more difficult for governments to act decisively. When multifactorial approaches are likely to be needed, this can make the 'ask' confusing - governments often want a clear plan, or a clear starting point. In some public health areas, it is often hotly contested where one should start.

With alcohol, at least in Australia, it is sometimes difficult to find the lever. Do we target individuals or the community? Consumers or business? And it can be even more perplexing with food, where mixed messages make the need to improve public awareness of the risks of obesity even more complicated.

The challenge to advocates on these issues and most other public health priorities is to find that lever - the right lever, at the right time for the decision maker you are trying to convince. Be careful, of course, not to weaken the argument by going in too many directions at once.
Developing alliances across consumers, clinicians, advocates and researchers will always be very powerful. The same proposal from multiple groups gives your argument weight and depth. Instead of all asking for something slightly different, if you can agree on one major initiative or a good starting point, it is a very much more convincing request. It automatically lifts it above the 20 other meetings and requests the minister has that day. You can be confident that everyone else asking the minister for something that day will probably not have done that work - so it is a way to make your cause better and more attractive, easier to sit up and take notice.

\section{Acknowledgements}

The interview was conducted by the Editor-in-Chief of Public Health Research \& Practice, Don Nutbeam.

\section{Copyright: (c)}

(C) 2017 Roxon. This article is licensed under the Creative Commons Attribution-NonCommercial-ShareAlike 4.0 International Licence, which allows others to redistribute, adapt and share this work non-commercially provided they attribute the work and any adapted version of it is distributed under the same Creative Commons licence terms. See: www.creativecommons.org/licenses/by-nc-sa/4.0/ 